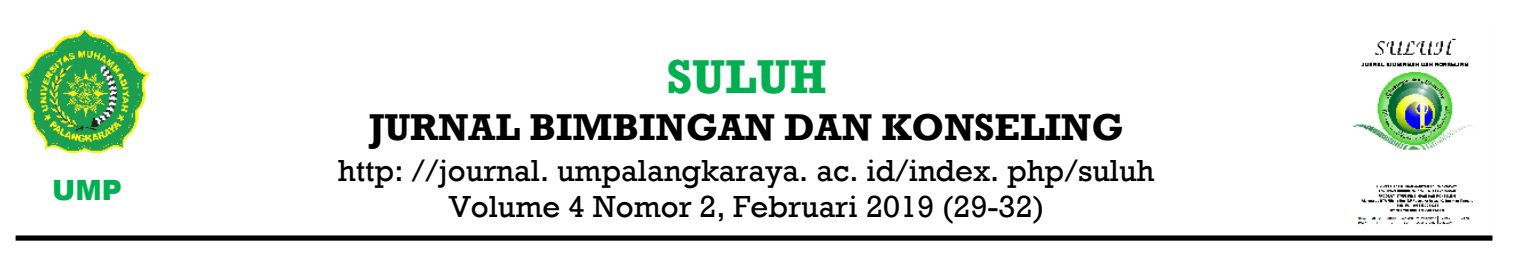

\title{
IMPLEIMENTASI LAYANAN BIMBINGAN KELOIMPOK UNTUK MENINGKATKAN PENYESUAIAN DIRI PESERTA DIDIK (Studi Kasus di SMA N 1 Palangkaraya)
}

\section{IMPLEMENTATION OF GROUP BANKING SERVICES FORINCREASING SELF- SUCCESSFUL PARTICIPANTS(Case Study in SMA N 1 Palangkaraya)}

\author{
'M. Fatchurahman, ${ }^{2}$ Rico Saputra \\ 'Universitas Muhammadiyah palangkaraya, Palangka Raya, Kalimantan Tengah, Indonesia \\ ${ }^{2}$ Universitas Muhammadiyah palangkaraya, Palangka Raya, Kalimantan Tengah, Indonesia
}

\begin{abstract}
ARTIKEL INFO
ABSTRAK

Diterima

Januari 2019

Tujuan dalam penelitian ini yaitu: (I) untuk mengetahui bentuk penyesuaian dir peserta didik kelas X MIA I SMAN-I Palangka Raya dan (2) untuk mengetahui implementasi layanan bimbingan kelompok oleh guru bimbingan konseling terhadap penyesuaian diri peserta didik. Penelitian ini menggunakan pendekatan kualitatif, dengan jenis penelitian studi kasus. Subjek penelitian terdiri dari I (orang) kepala sekolah, I (orang) guru bimbingan dan konseling dan 6 (enam) orang peserta didik. Teknik pengumpulan data menggunakan observasi, wawancara, dan dukumentasi. Hasil yang diperoleh dalam penelitian ini dapat disimpulkan yaitu: (I) Proses penyesuaian diri dapat dengan cara menerima keadan diri sendiri, mampu terbuka

Dipublikasi

Februari 2019 pada teman-teman sebayanya, mampu memilah dan memiliki sesu atau hal yang baik dan yang buruk, serta mampu mengendalikan emosi. Faktor-faktor yang mempengaruhi penyesuaian diri yaitu psikogenik (hubungan di dalam keluarga) dan sosiopsikogenik (lingkungan sekolah dan sosial). (2) L ayanan bimbingan kelompok dilaksanakan, akan tetapi tidak secara kontinyu. Pelaksanaan layanan bimbingan kelompok sudah melewati tahapan yang sudah baku (tahap pembentukan, peralihan, kegiatan, dan pengakhiran) akan tetapi kegiatan yang dilakukan di dalam setiap tahapannya belum sesuai dengan konsep yang ideal.
\end{abstract}

*E-mail:

andiysetiawan@gmail.com

Kata Kunci: Penyesuian Diri dan Bimbingan Kelompok.
Orchid:

(ansetiawan@g

Orchid:

\begin{abstract}
The objectives of this study were: (I) to find out the form of self-adjustment for students of class X MIA I of SMAN-I Palangka Raya and (2) to find out the implementation of group guidance services by counseling teachers on students' self-adjustments. This study uses a qualitative approach, with a type of case study research. The research subjects consisted of I (person) headmaster, I (person) guidance and counseling teacher and 6 (six) students. The technique of collecting data uses observation, interviews, and documentation. The results obtained in this study can be concluded, namely: (I) The process of self-adjustment can be by accepting one's own self, being able to be open to peers, able to sort out and have good or bad things, and be able to control emotions. Factors that influence selfadjustment are psychogenic (family relationships) and sociopsychogenic (school and social environment). (2) A group guidance service is implemented, but not continuously. The implementation of group guidance services has passed the standard stages (formation, transition, activities, and termination stages) but the activities carried out in each stage are not in accordance with the ideal concept.Keywords: Self Adjustment and Group Guidance.
\end{abstract}

Keywords: Role of Counselors, Free Intercourse 
Jurnal Bimbingan dan Konseling

\section{PENDAHULUAN}

Penyesuian diri sangat penting bagi peserta didik, karena pada saat peserta didik mulai menumpuh pendidikan, setiap peserta didik akan berbaur dengan banyak orang dan wajib mematuhi peraturan yang berlaku di sekolah, disinilah peserta didik rentang terjadi permasalahan, seperti penyesuaian dirinya terhadap lingkungan baru disekolah tersebut. Peserta didik masih belum mengenal antara teman-temannya, antara guru, dan lingkungan sekolahnya, maka akan sulit bagi peserta didik untuk bisa menyesuaikan dirinya terhadap lingkungan baru tersebut. Fatimah (2006:193) bahwa penyesuaian diri yang sehat terhadap lingkungan merupakan salah satu prasyarat yang penting bagi terciptanya kesehatan jiwa/mental individu. Banyak individu yang menderita dan tidak mampu mencapai kebahagian dalam hidupnya karena ketidakmampuannya dalam menyesuaikan diri dengan kehidupan masyarakat dan llingkungan sekolahnya.Peserta didik kelas X SMA sedang memasuki lingkungan baru,lingkungan yang berbeda dengan masa lingkungan yang sebelumnya.

Hal ini berpotensi menyebabkan timbulnya masalah-masalah baru dalam dirinya termasuk masalah penyesuaian diri yang rendah antara lain penyesuian diri dengan guru, teman, dan lingkungan sekolahnya. Berdasarkan hasil observasi dan data-data yang diambil oleh peneliti di SMAN-I Palangka Raya, fenomena permasalahan penyesuaian diri pada peserta didik kelas $X$ MIA-I, fenomena itu dapat dilihat dari kurangnya keakraban sesama teman sebaya, tidak dapat berkomunikasi dan beritraksi dengan baik antara sesama teman sebayanya maupun dengang guru serta dengan kondisi lingkungan sekolah tersebut, sehinnga membuat peserta didik tidak percaya diri, tidak bisa bergaul dengan teman-teman barunya disekolah tersebut, karena mereka masih belum mengenal satu sama lainnya. Hal seperti ini akan menghambat peserta didik dalam membiasakan dirinya untuk dapat saling berbagi dan bergaul antara teman sebayanya karena masih kurangnya penyesuaian diri pada masing-masing peserta didik.

Chamad (2009: 23) bimbingan kelompok merupakan bantuan terhadap individu yang dilaksanakan dalam situasi kelompok. Bimbingan kelompok dapat berupa penyampaian informasi ataupun aktifitas kelompok membahas masalah-masalah pendidikan, pekerjaan, pribadi, dan sosial. Melihat fenemona tersebut, maka peneliti akan melakukan penelitian: "Implementasi Layanan Bimbingan Kelompok Untuk Meningkatkan Penyesuaian Diri Peserta Didik Kelas X MIA I SMAN-I Palangka Raya”.

Dalam penelitian ini peneliti ingin melihat bagaimana implementasi layanan bimbingan kelompok yang diberikan oleh guru BK SMAN I Palangka Raya kepada peserta didik kelas X MIA I SMAN-I Palangka Raya agar dapat meningkatkan kemampuan penyesuaian diri di lingkungan sekolah.Berdasarkan fenomena yang ditemui peneliti maka tujuan yang ingin dicapai dari penelitian ini adalah sebagai berikut: Untuk mengetahui bentuk penyesuaian diri peserta didik kelas X MIA I SMAN-I Palangka Raya dan Untuk mengetahui implementasi layanan bimbingan kelompok yang dilaksanakan guru BK untuk meningkakan penyesuaian diri pesera didik kelas X MIA I SMAN-I Palangka Raya.

\section{METODE PENELITIAN}

Penelitian ini menggunakan pendekatan kualitatif. Sugiyono (2014:I) metode penelitian kualitatif adalah metode penelitian yang digunakan untuk meneliti pada kondisi obyek yang alamiah, dimana penelitian adalah sebagai instrumen kunci, teknik pengumpulan data dilakukan secara trianggulasi (gabungan), analisis data bersifat induktif, dan hasil 
penelitian kualitatif lebih menekan makna dari pada generalisasi.

Jenis penelitian dalam penelitian ini yaitu menggunakan penelitian studi kasus. Jenis penelitian studi kasus adalah penelitian yang menyajikan subjek penelitian yang detail mengenai kondisi tertentu secara keseluruhan personalitas dalam kehidupan sehari- hari. Subjek penelitian terdiri dari I (orang) kepala sekolah, I (orang) guru bimbingan dan konseling dan 6 (enam) orang peserta didik. Teknik pengumpulan data menggunakan observasi, wawancara, dan dukumentasi.

\section{HASIL DAN PEMBAHASAN}

Proses penyesuaian diri merupakan suatu tuntutan yang harus peserta didik penuhi agar dapat menerima dirinya dengan baik, dapat diterima dalam lingkungan masyarakat, dan lingkungan sekolah. Proses penyesuaian diri dapat dilakukan peserta didik yaitu dengan cara menerima keadan diri sendiri, mampu terbuka pada teman-teman sebayanya, mampu memilah dan memiliki sesuatau hal yang baik dan yang buruk, serta mampu mengendalikan emosionalnya dengan baik. Kesulitan yang dialami Peserta Didik $X$ MIA I dalam penyesuain diri diantaranya adalah kesulitan bergaul, tidak memahami peraturan sekolah, tidak bisa menyesuaikan diri dengan metode pembelajaran yang di berikan oleh guru dan cendrung berkonflik dengan teman sebaya. Pada tahap ini beberapa Peserta Didik kelas X MIA I juga tengah menjalani proses menjadi mandiri dari. Jika Peserta Didik merasa aman dengan semua hubungan sosial yang dijalaninya, maka dia akan merasa bebas menggunakan sebagian besar usahanya untuk belajar. Jika tidak, maka akan muncul kemungkinan terganggunya konsentrasi belajar Peserta Didik tersebut hal ini akan membuat prestasi belajar Peserta Didik menjadi menurun.
Peserta Didik $X$ MIA I yang mempunyai masalah penyesuaian diri cenderung lambat dalam memahami setiap materi pelajaran yang disampaikan dan cenderung menutup diri serta memperlihatkan perilaku yang tidak biasa, dikelas biasanya Peserta Didik cenderung menutup diri, tidak terlibat dalam kegiatan yang diadakan sekolah, atau reaksi yang ditampilkan saat tersinggung mudah marah atau menentang. Cara berpikir yang dimiliki beberapa Peserta Didik kelas $X$ MIA I merupakan dasar untuk mengevaluasi pengalaman-pengalaman baru yang diterima di sekolah yang baru, sebagai konsekwensinya beberapa Peserta Didik kelas $X$ MIA I cenderung untuk mempertahankan cara berpikir yang sudah dimilikinya dan menolak informasi baru yang berlainan. $\mathrm{Hal}$ ini yang menyebabkan Peserta Didik mengalami masalah dalam penyesuaian diri di lingkungan sekolah. Bentuk penyesuaian diri Peserta Didik akan berubah mengikuti peraturan dan kebiasaan yang ada di lingkungan yang baru yaitu lingkungan sekolah, dan kemampuan penyesuain diri Peserta Didik berbedabeda tergantung seberapa cepat Peserta Didik memahami peraturan yang ada dan menerapkan peraturan tersebut.

\section{KESIMPULAN}

Kesulitan yang dialami peserta didik $X$ MIA I dalam penyesuain diri diantaranya adalah kesulitan bergaul, tidak memahami peraturan sekolah, tidak bisa menyesuaikan diri dengan metode pembelajaran yang di berikan oleh guru, cenderung menutup diri, tidak terlibat dalam kegiatan yang diadakan sekolah, dan reaksi yang ditampilkan saat tersinggung mudah marah. Sedangkan peserta didik kelas $X$ MIA I yang memiliki kemampuan penyesuaian diri yang baik akan menunjukan beberapa perilaku yaitu: Tidak 
Jurnal Bimbingan dan Konseling

akan emosi secara berlebihan (marah atau tersinggung) apabila menghadapi situasi yang tidak sesuai dengan harapannya, Peserta Didik juga tidak merasa tertekan mengikuti peraturan yang ada di sekolah, Apabila Peserta Didik memiliki masalah Peserta Didik tersebut mampu memecahkan masalah tersebut dengan pertimbangan yang matang dan Peserta Didik memiliki kemauan untuk mengembangkan diri dengan mengikuti kegiatan-kegiatan yang ada di sekolah maupun diluar sekolah.

Layanan bimbingan kelompok dilaksanakan, akan tetapi tidak secara kontinyu. Guru bimbingan dan konseling biasanya melaksanakan layanan pada jam istirahat atau saat ada jam kosong, agar tidak mengganggu kegiatan belajar Peserta Didik pada jam pelajaran yang lain. Pelaksanaan layanan bimbingan kelompok di kelas X MIA I SMAN I Palangka Raya sudah melewati tahapan yang sudah baku akan tetapi kegiatan yang dilakukan di dalam setiap tahapannya belum sesuai dengan konsep yang ideal.

\section{DAFTAR PUSTAKA}

Achamad. J. H. 2006. Bimbingan \& Konseling dalam Berbagai Latar Belakang.Bandung: PT Rafika Aditama.

Agustiani Hendrianti. 2006. Psikologi Perkembangan (Pendekatan Ekologi Kaitannya dengan Konsep Diri dan Penyesuain Diri pada Remaja). Bandung: PT Rafika aditama.

Arista Kiswantoro. 20I5. Model Bimbingan Kelompok Dengan Teknik Life Model Untuk Meningkatkan Rasa Percaya Diri

Atlet Persina Asad Kabupaten Kudus. ISSN 2460- I I87.

Desmita. 2014. Psikologi Perkembangan pesesrta didik Bandung: Remajo Rosda Karya.

Fatimah Enung. 2006. Psikologi Perkembangan (Perkembangan Peserta Didik). Bandung: Pustaka Setia.
Nurnaningsih. 20II. Bimbingan Kelompok Untuk Meningkatkan Kecerdasan Emosional Siswa. ISSN 14I2-565X.

Sobur.A. 2013. Psikologi umum dalam lintasan sejarah. Bandung: CV Pustaka Setia.

Sugiyono. 2014. Memahami Penelitian Kualitatif. Bandung: Alfabeta

'M. Fatchurahman, ${ }^{2}$ Rico Saputra 